SUPPORTING INFORMATION

\title{
Bayesian Machine Learning for Efficient Minimization of Defects in ALD Passivation Layers
}

Gül Dogan 1,2, , Sinan O. Demir ${ }^{2}$, Rico Gutzler ${ }^{3}, H_{\text {Herbert Gruhn }}^{4}$, Cem B. Dayan', Umut T. Sanli $^{2}$, Christian Silber ${ }^{1}$, Utku Culha ${ }^{2, *},{ }^{*}$, Metin Sitti $^{2}$, Gisela Schütz ${ }^{2}$, Corinne Grévent ${ }^{1}$, and Kahraman Keskinbora ${ }^{2, *, \dagger}$

${ }^{1}$ Robert Bosch GmbH, Automotive Electronics, Postfach 13 42, 72703 Reutlingen, Germany

2 Max Planck Institute for Intelligent Systems, Heisenbergstr 3, 70569 Stuttgart, Germany

${ }^{3}$ Max Planck Institute for Solid State Research, Heisenbergstr 1, 70569 Stuttgart, Germany

${ }^{4}$ Robert Bosch GmbH, Corporate Sector Research and Advance Engineering, Robert-BoschCampus1, 71272 Stuttgart, Germany

$\dagger$ Current address:

Munich School of Robotics and Machine Intelligence, Technical University of Munich, 80797

Munich, Germany

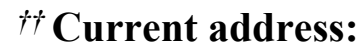

Massachusetts Institute of Technology, 77 Mass Avenue, Cambridge, MA 02139, USA

*Corresponding Authors:

kahraman@mit.edu, utku.culha@tum.de, guel.dogan@de.bosch.com

Keywords: Atomic layer deposition, copper, defect density, wet etching, Bayesian optimization 


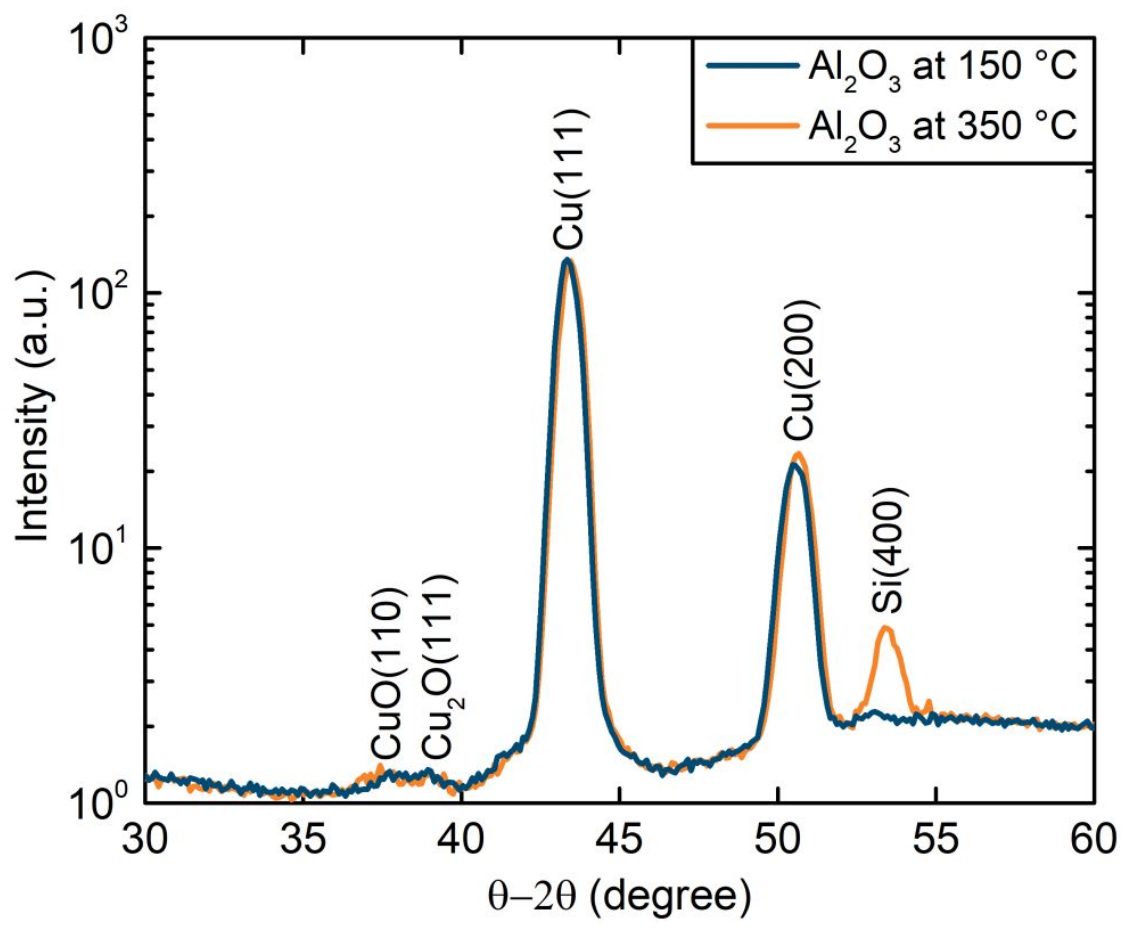

Figure S1. GI-XRD of $\mathrm{ALD}-\mathrm{Al}_{2} \mathrm{O}_{3}$ on copper for lowest and highest deposition temperatures that used in this work. Both diffraction data showed the amorphous phase of $\mathrm{Al}_{2} \mathrm{O}_{3}$. The $\mathrm{Cu}$ (111) and (200) metallic peaks were detected additional of the broad peak at around $38^{\circ}$ which was the mixture of copper oxide phase. The $\mathrm{Si}(400)$ peak came from the substrate which depends on the relative in-plane orientation of the substrate with respect to the measurement direction. It does not signify a crystallographic change in the structure. 


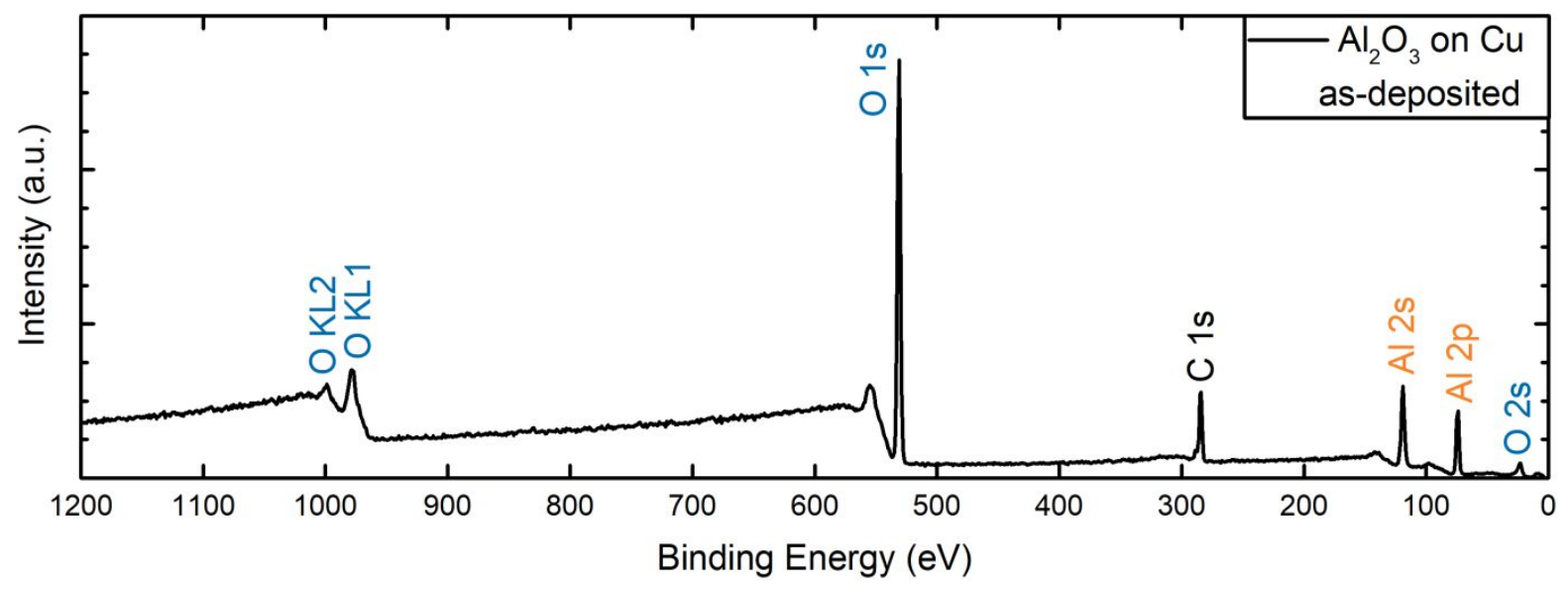

Figure S2. XPS survey spectra for as-deposited $\mathrm{Al}_{2} \mathrm{O}_{3}$ reference sample. The $\mathrm{Al}$ and $\mathrm{O}$ atoms were detected on the surface, additional with $\mathrm{C}$ which comes from the environment. According to curve fitting of the survey spectra, oxygen was found 47.6 at.\% and aluminum was 33.25 at.\% which indicates the formation of $\mathrm{Al}_{2} \mathrm{O}_{3}$ with [Al:O]: 0.6 atomic ratio. 

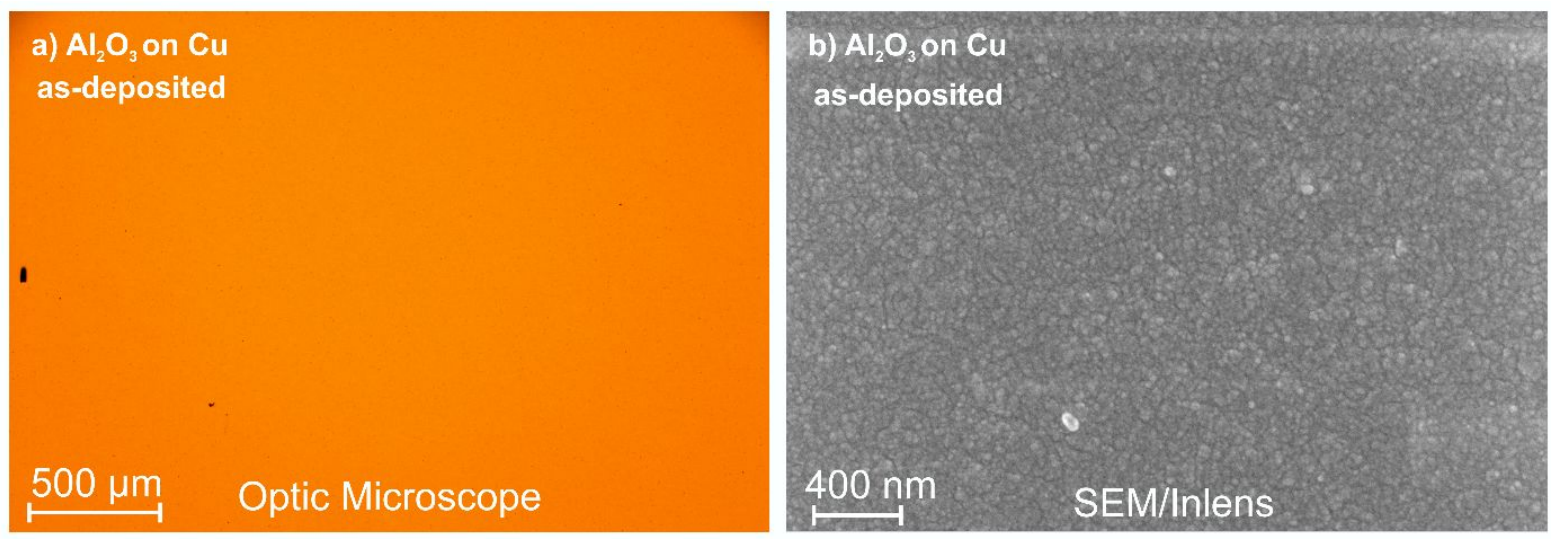

Figure S3. Surface properties of $\mathrm{Al}_{2} \mathrm{O}_{3}$ (a) optic microscope and (b) SEM before wet etching. The SEM images were taken in $2 \mathrm{keV}$ with an Inlens detector. The reference ALD parameters were used for $\mathrm{Al}_{2} \mathrm{O}_{3}$ deposition $\left(150^{\circ} \mathrm{C}, 20 \mathrm{~ms}\right.$, without plasma pretreatment). 

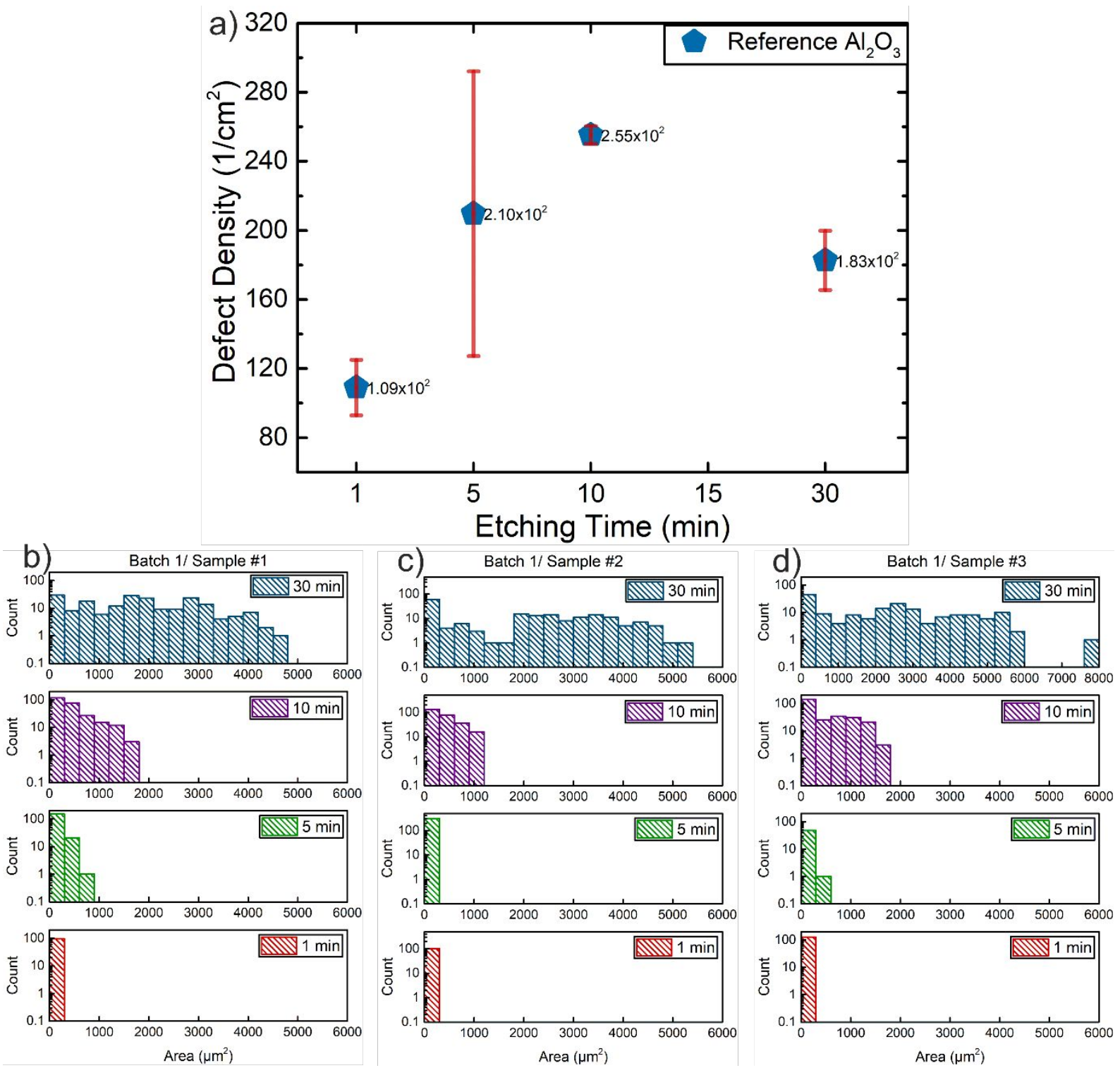

Figure S4. Wet etching time dependency of $\mathrm{Al}_{2} \mathrm{O}_{3}$ reference sample. (a) Defect density in $\mathrm{cm}^{2}$ for different etching times. The standard deviations were calculated based on three different samples. The defect size distribution for different etching times is given for (b) sample 1, (c) sample 2, and (d) sample 3. While the defect density was 109 in $1 \mathrm{~cm}^{2}$, it was getting similar, around $200 \mathrm{1} / \mathrm{cm}^{2}$, for $5 \mathrm{~min}, 10 \mathrm{~min}$, and $30 \mathrm{~min}$. According to particle distribution, the smaller defects were getting larger with longer penetration but as well new defects started to reveal on the surface. It shows the longer acid penetration provides the overall defect structure with the existence of all types of defect. 


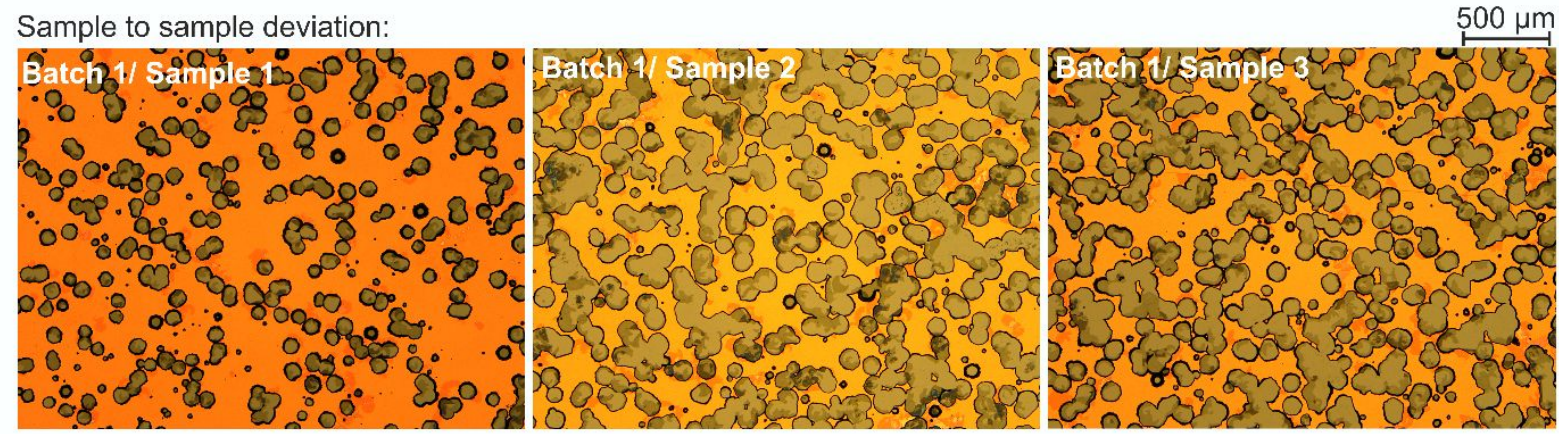

Batch to batch deviation:
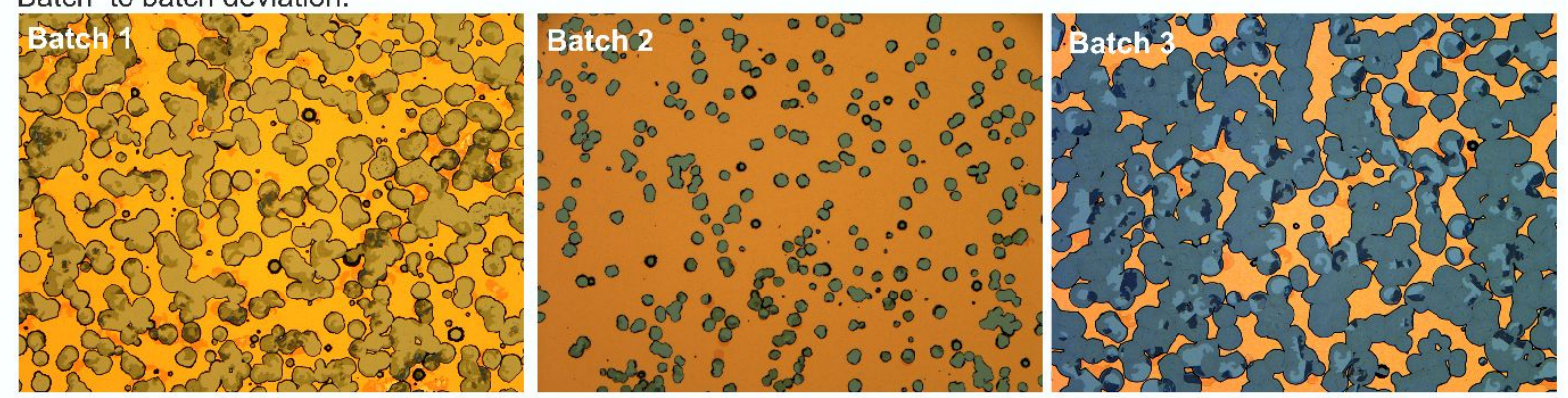

Figure S5. The defect density of reference $\mathrm{Al}_{2} \mathrm{O}_{3}$ films after $30 \mathrm{~min}$ nitric acid etching. While sample to sample deviation was found $39.35 \pm 10.51$ for batch 1 , it was found $17.54 \pm 2.02$ and $77.92 \pm 13.62$ for batch 2 and 3, respectively. The overall etched area and standard deviation for reference $\mathrm{Al}_{2} \mathrm{O}_{3}$ films was found $44.935 \pm 27.323$. 


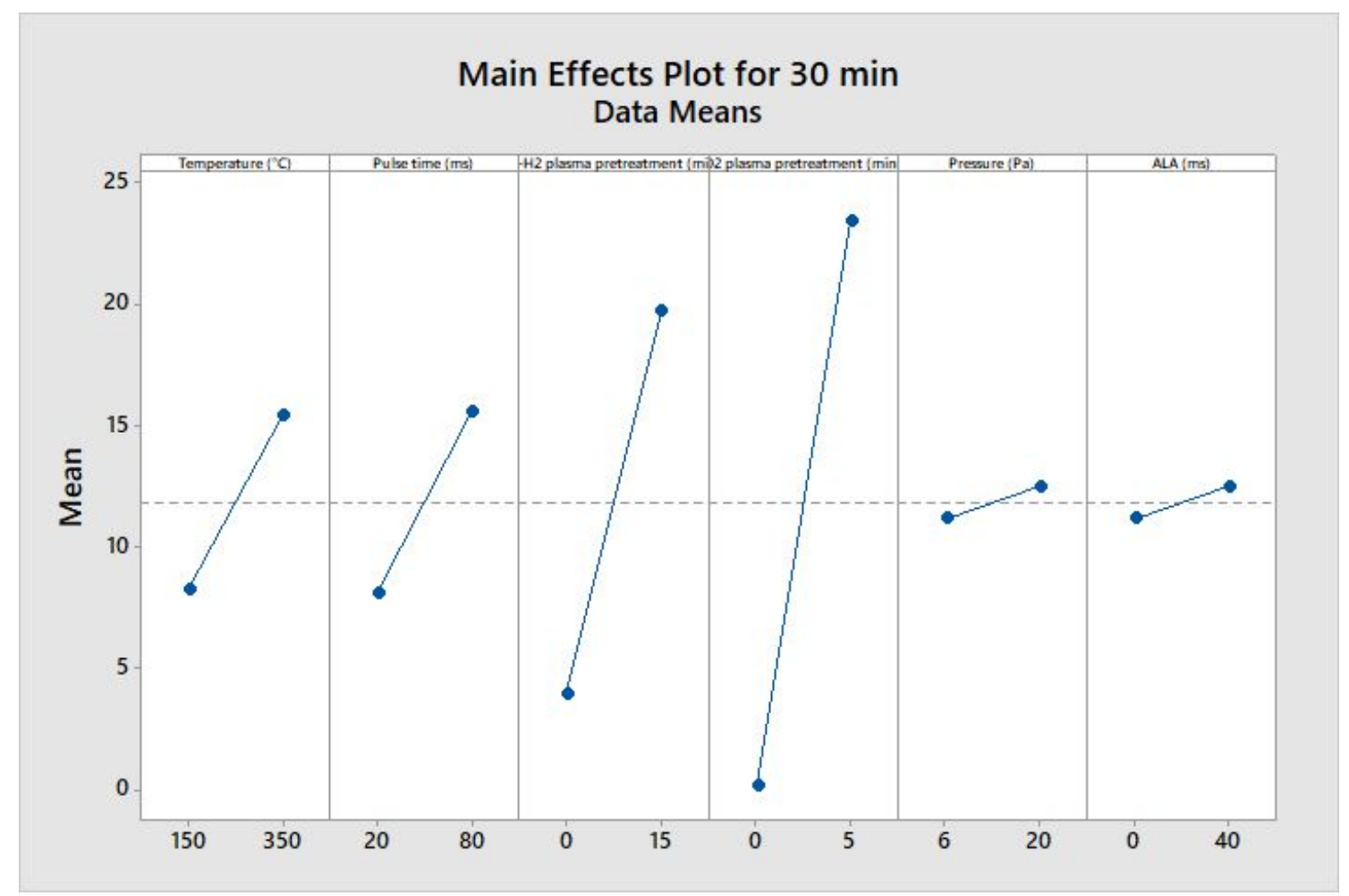

Figure S6. The main effect plot for defect density of $\mathrm{Al}_{2} \mathrm{O}_{3}$ films according to two-level FFD analysis with six parameters. According to the main effects plot, $\mathrm{O}_{2}$ plasma considerably affected the defect density but in an antagonistic manner (negative effect of a parameter). The $\mathrm{Ar} / \mathrm{H}_{2}$ plasma pretreatment was also found to have an important effect on defect density. The temperature and pulse time was considered relatively important, and have the same effect magnitude. The pressure and additional waiting time between cycles (ALA) were considered to have a low effect on defect density. While $\mathrm{O}_{2}$ was found significant, it was omitted from the optimization step due to its undesired effect on defect density. 

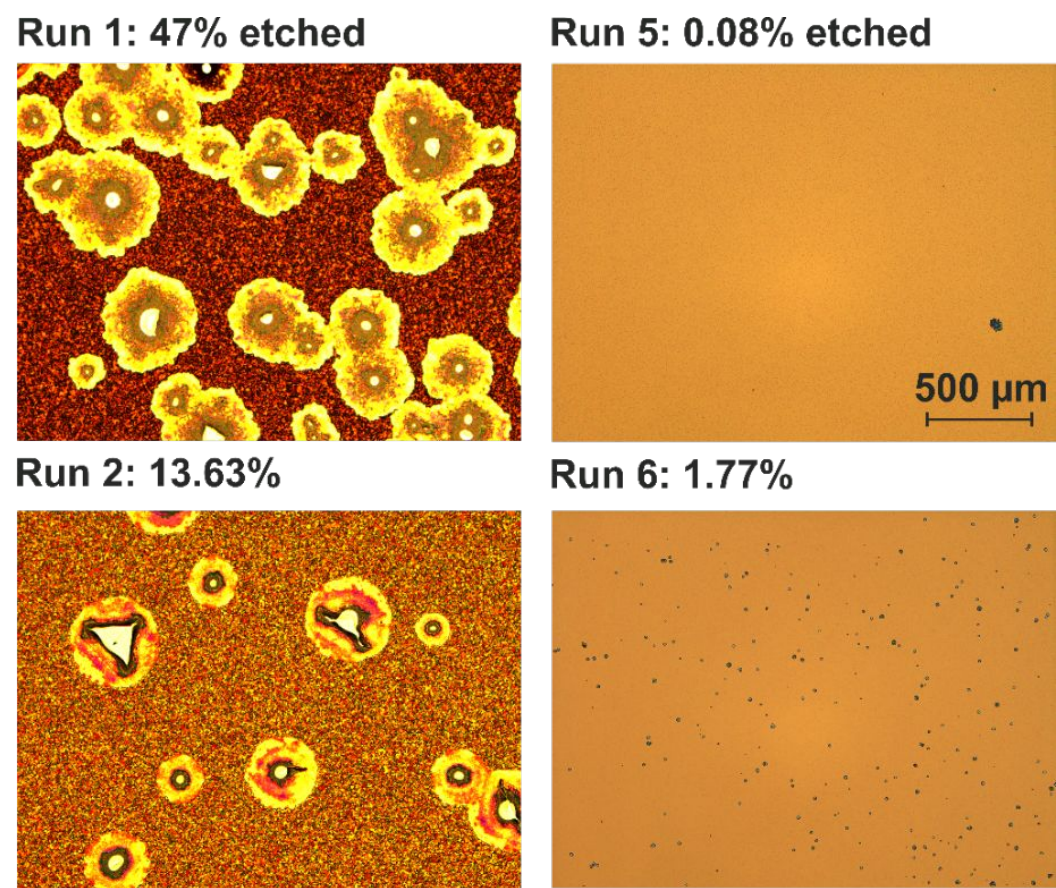

Run 6: $1.77 \%$

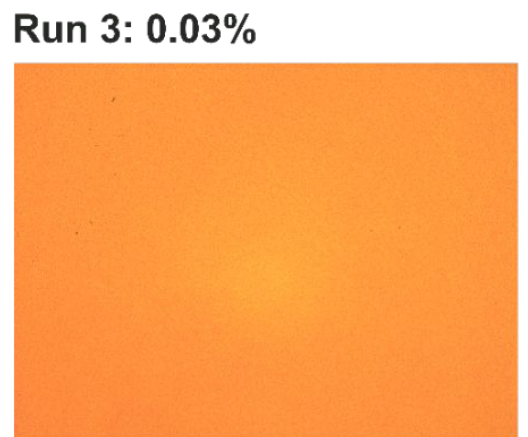

\section{Run 4: $1.03 \%$}

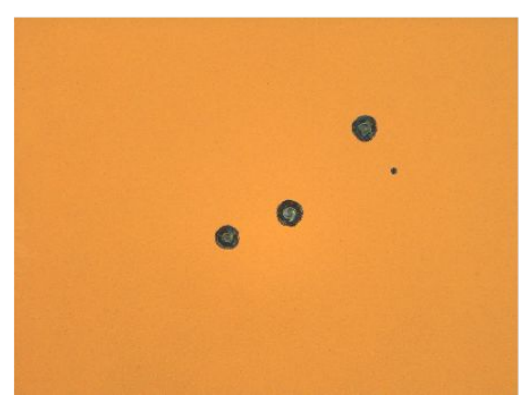

Run 7: $0.289 \%$
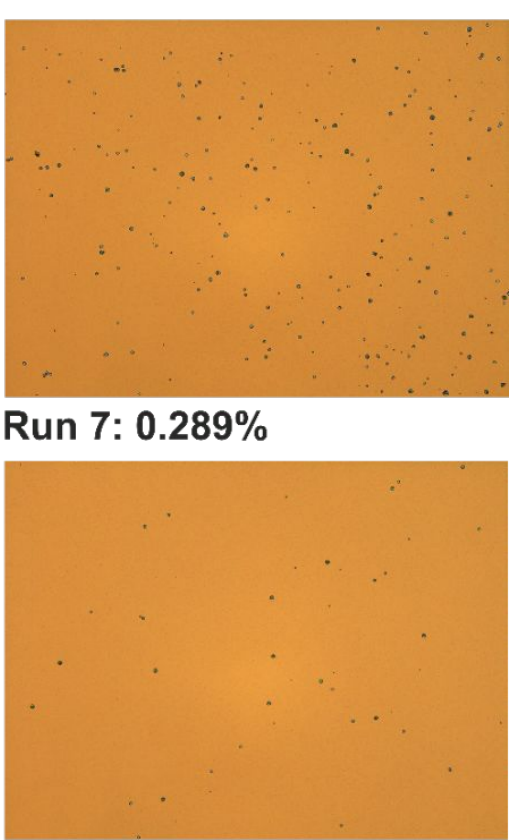

Run 8: $30.7 \%$

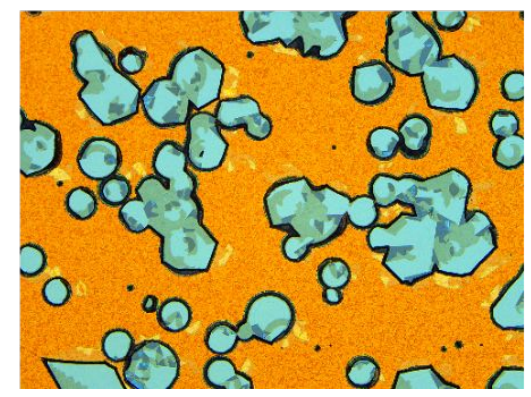

Figure S7. The optic microscope images for $30 \mathrm{~min}$ wet etching as a result of two-level screening FFD analysis. All optic microscope images were taken with x5 magnification, as indicated in Run5-500 $\mu \mathrm{m}$. 


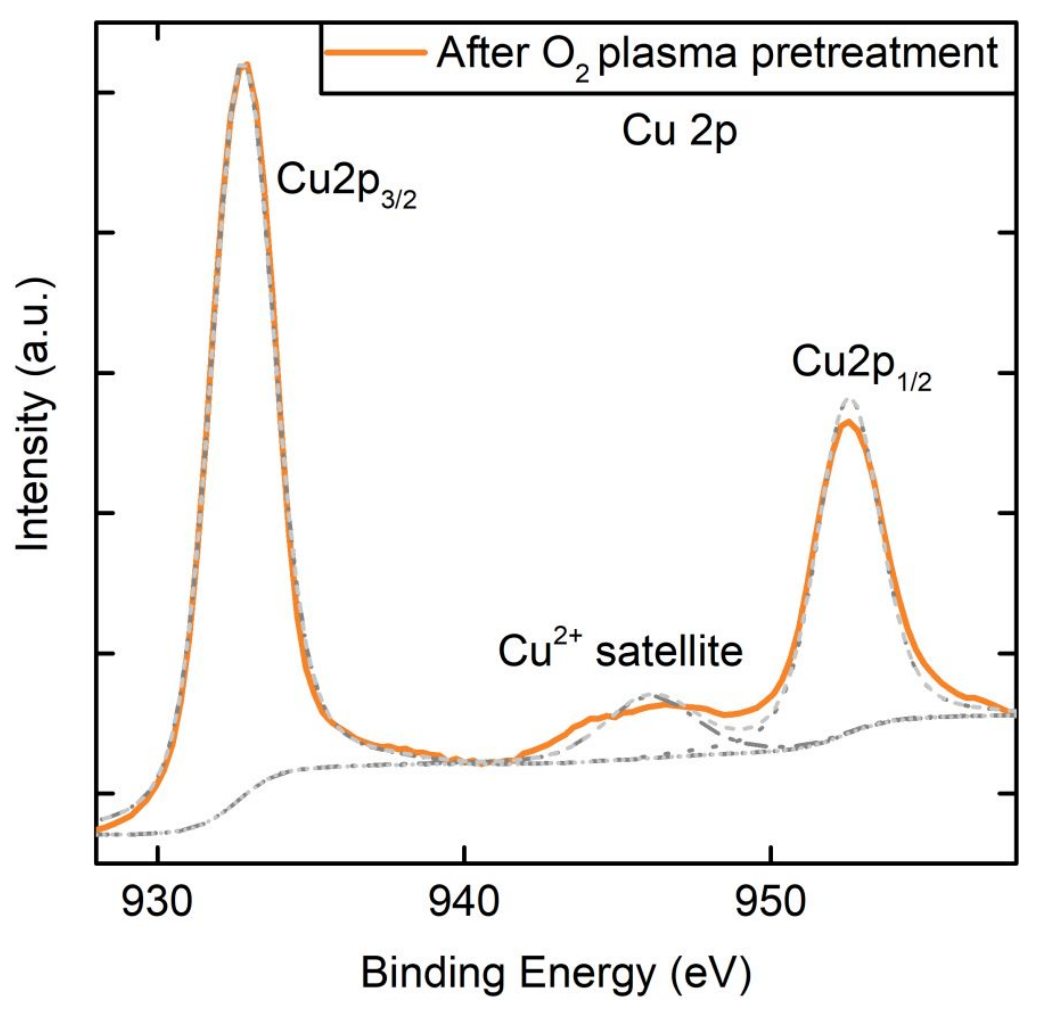

Figure S8. XPS of copper peaks from the surface of $\mathrm{O}_{2}$ plasma pretreated copper shows the presence of oxide formation. The coper peaks were labeled at $834.5 \mathrm{eV}$ and $954.2 \mathrm{eV}$ and strong $\mathrm{Cu}^{2+}$ satellite peak at $944.7 \mathrm{eV}$ which were referenced to copper oxide formation. The $\mathrm{O}_{2}$ plasma pretreatment was applied at $350{ }^{\circ} \mathrm{C}$ for $5 \mathrm{~min}$. According to in situ spectroscopic ellipsometry measurements, the copper oxide thickness was measured $\sim 2.5 \mathrm{~nm}$ before treatment, and $\sim 155$ nm after treatment. 


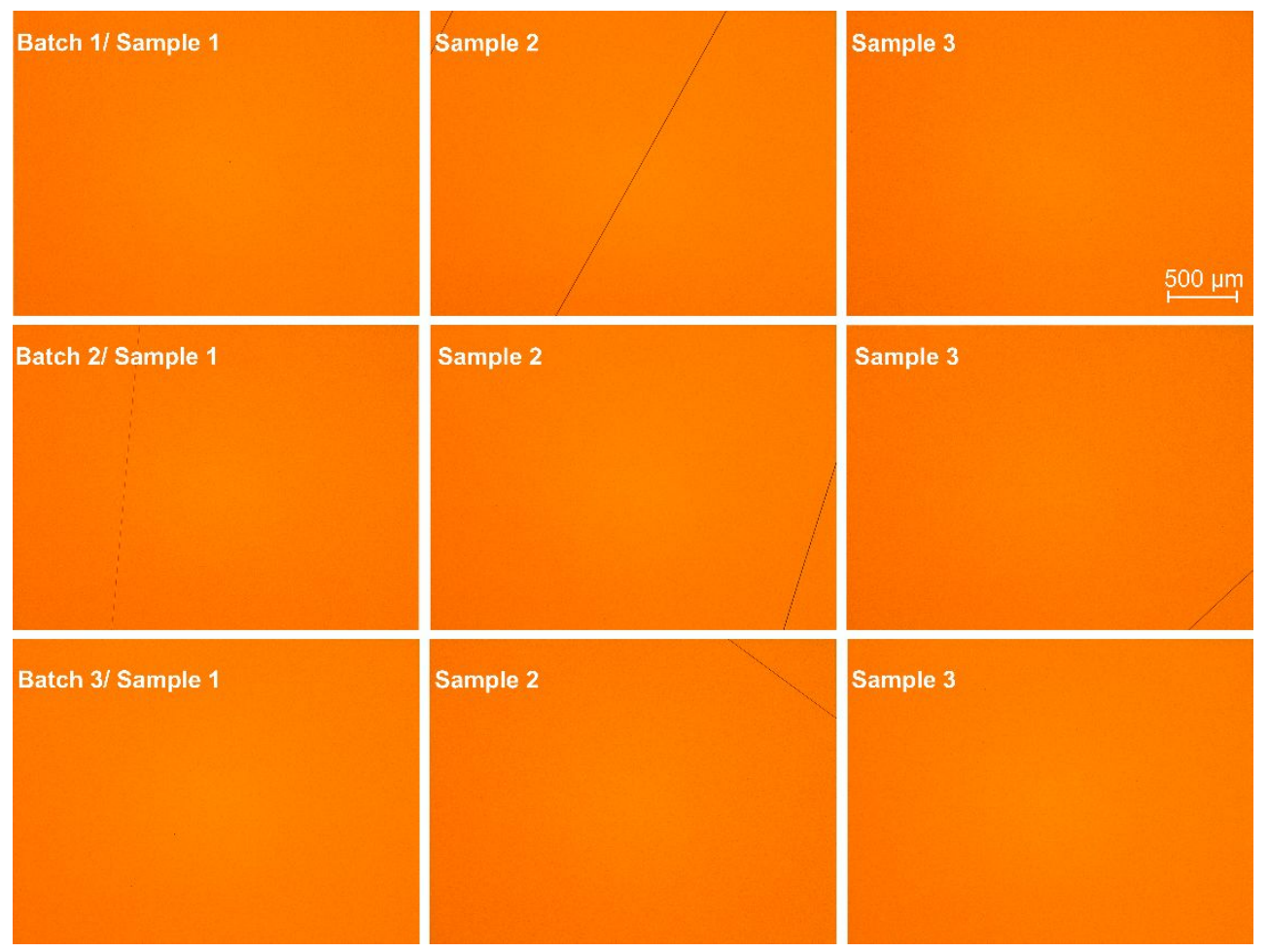

Figure S9. Optic microscope images for repeatability of optimum process parameters (step 3.6) by $30 \mathrm{~min}$ wet etching. The same experimental parameters were applied three times (batch deviation) in which 3 samples were placed in each case (sample deviation). The sample to sample deviation was calculated for each batch and indicated as average value and standard deviation. The batch to batch deviation was calculated based on the average value with error propagation analysis. Table S1 summarized the calculated values.

Table S1. Repeatability of optimum state defect density for $\mathrm{Al}_{2} \mathrm{O}_{3}$ films

\begin{tabular}{ccc}
\hline & \multicolumn{2}{c}{ Defect Density (\%) } \\
\hline Batch 1 & 0.0027 & \pm 0.0012 \\
Batch 2 & 0.0032 & \pm 0.0003 \\
Batch 3 & 0.0037 & \pm 0.0017 \\
\hline Batch to Batch & 0.0033 & \pm 0.0011 \\
\hline Step 3.6 & 0.0014 & \pm 0.0007 \\
\hline
\end{tabular}


Table S2. Additional experiment details that were used during parameters effect analysis in Bayesian Optimization. The experiments were conducted during parameters limit search to identify the low and high levels in FFD analysis. Additionally, Run 3 from FFD analysis was also added as other parameters were in the reference case.

\begin{tabular}{ccccc}
\hline \multirow{2}{*}{ Experiments } & Pretreatment & \multicolumn{2}{c}{ ALD process parameters } & \\
\cline { 2 - 4 } & $\begin{array}{c}\text { Ar- } \mathrm{H}_{2} \text { plasma } \\
(\mathrm{min})\end{array}$ & $\begin{array}{c}\text { Temperature } \\
\left({ }^{\circ} \mathrm{C}\right)\end{array}$ & $\begin{array}{c}\text { Pulse } \\
\text { time } \\
(\mathrm{ms})\end{array}$ & $\begin{array}{c}\text { Etched Area } \\
(\%)\end{array}$ \\
\hline 1 & 0 & 350 & 80 & 0.09 \\
2 & 15 & 150 & 20 & 0.5 \\
3 & 15 & 150 & 80 & 0.17 \\
4 & 15 & 350 & 80 & 0.02 \\
Run 3 (FFD) & 15 & 350 & 20 & 0.004 \\
\hline
\end{tabular}




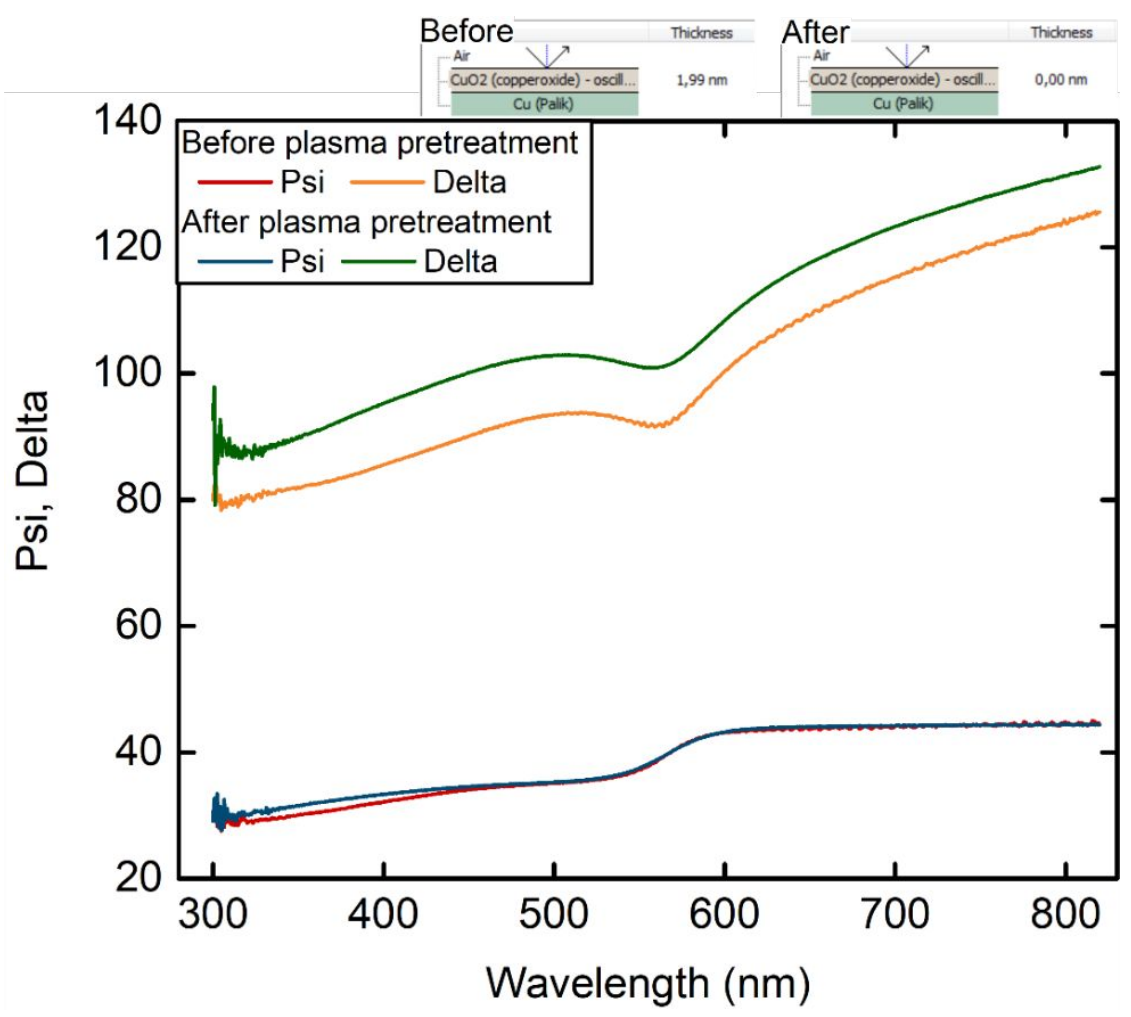

Figure S10. By application of the plasma pretreatment, the air-formed oxide layer was removed according to the in situ spectroscopic ellipsometry (SE) data. The psi and delta plot is given as a function of wavelength. Before $\mathrm{Ar} / \mathrm{H}_{2}$ plasma pretreatment, in situ $\mathrm{SE}$ measurement showed $1.99 \mathrm{~nm} \mathrm{Cu}_{2} \mathrm{O}$ thickness according to the fitting analysis of psi and delta curves. With the application of $5 \mathrm{~min} \mathrm{Ar} / \mathrm{H}_{2}$ plasma pretreatment at $250{ }^{\circ} \mathrm{C}$, the thickness of $\mathrm{Cu}_{2} \mathrm{O}$ found zero, indicated by the change of delta curve. For the optical model, copper was defined as the file layer, and $\mathrm{Cu}_{2} \mathrm{O}$ layer according to Drude and Lorentz oscillator. The model-fitting results are given on the top of the figure for before and after plasma pretreatment with $1.99 \mathrm{~nm}$ and $0 \mathrm{~nm}$ $\mathrm{Cu}_{2} \mathrm{O}$ thickness, respectively. 


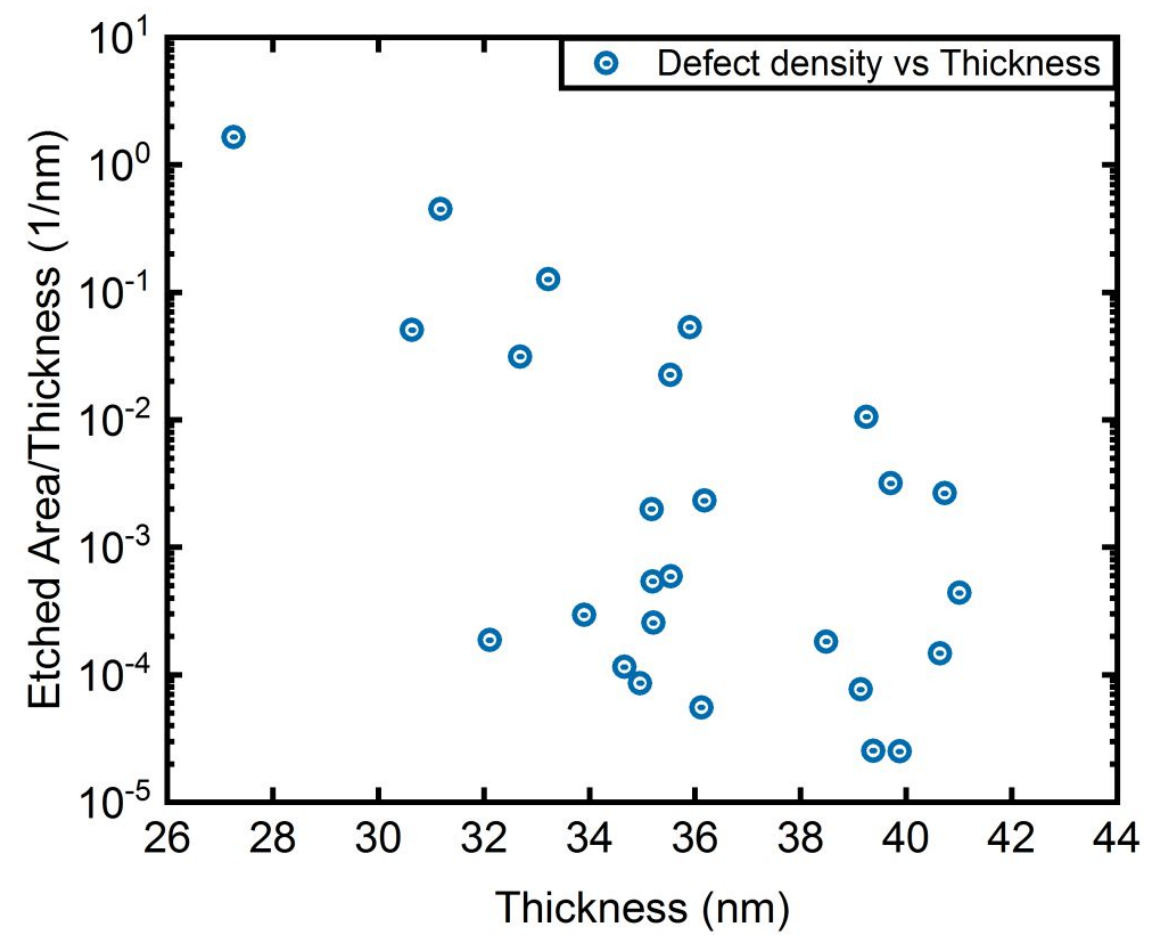

Figure S11. Etched area percentage per thickness (1/nm) for $\mathrm{ALD}-\mathrm{Al}_{2} \mathrm{O}_{3}$ thin films at different process parameters. For the films deposited with optimized parameters, the defect density per deposited thickness (etched area $\% / \mathrm{nm}$ ) does not depend significantly on the thickness. In other words, depositing more material for optimized films does not increase the corrosion protection properties. 